Forthcoming Commentary - Journal of Epidemiology Community Health

\title{
Social relationships at work and depression
}

Roberto De Vogli ${ }^{1} \mathrm{PhD}, \mathrm{MPH}$

${ }^{1}$ Department of Epidemiology and Public Health, University College London.

Words text: 798

References: 14

Correspondence to: Roberto De Vogli, International Institute for Society and Health, Department of Epidemiology and Public Health, University College London. 1-19 Torrington Place, London WC1E 6BT, (email: r.devogli@ucl.ac.uk). 
There is a quite large body of evidence indicating that social relationships are important determinants of health $[1,2]$. The benefits of social relationships have been observed in multiple settings including the work environment [3] and they extend not only to physical health but also mental health [4]. In this issue of JECH, Oksanen and colleagues show that distrustful, disrespectful and uncooperative social relationships at work are independent predictors of physician-diagnosed depression and antidepressant treatment [5]. Their study demonstrated that both the "horizontal" and "vertical" components of social relationships at work exert an independent effect on depression. The interest of their study is that it demonstrates that not only negative social relationships among co-workers make people feel miserable, but also "toxic" social exchanges with bosses and supervisors.

In a way, such findings are not surprising, however. People deeply care about how they are treated by others in equal or higher positions in the social hierarchy and there is substantial evidence indicating that unfair treatment [6] and lack of social support [7] can generate adverse emotional reactions and depressive symptoms. The specific mechanisms explaining why negative social interactions with co-workers and bosses can make people feel depressed remain largely unexplored. The authors attempted to address these mechanisms by investigating the role of health behaviours in mediating the association between social relationships at work and depression. Their findings showed that health behaviours attenuate the associations between horizontal and vertical social relationships by only 4-7\%. Alternative mechanisms have not been explored. It would have been important, for example, to investigate the role of factors such as hopelessness, low control, self-esteem, sense of unfairness and alienation in 
mediating the association between workplace social relationships and depression. However, the study by Oksanen and colleagues was not equipped to examine these mechanisms.

Oksanen and colleagues have also examined the gender-specific effects of workplace social relationships on depression. Their analyses do not show the existence of a statistical interaction between gender and horizontal and vertical components of social relationships. However, study participants were predominantly women (about $82 \%$ of the sample) and the odds of depression and new antidepressant treatment (after adjusting for socio-demographic characteristics) were much higher for men than for women. Such results seem to suggest that there could be a gender effect making negative social relationships at work stronger risk factors of depression for men than for women. Perhaps these differences could be attributed to gender differences in terms of sense of identity and social role as well as life aspirations and emotional and copying styles.

At the end of their article, Oksanen and colleagues suggest that intervention studies are needed to determine whether enhancing horizontal workplace social relationships among equals and vertical workplace social relationships across power gradients would reduce the risk of depression. This is certainly a potentially plausible solution to reduce depression and negative social relationships at work. The problem with tailored workplace interventions such as the ones suggested by Oksanen and colleagues, however, is that interpersonal exchanges both at the horizontal and vertical levels are largely influenced by the social and structural organization of society. For example, evidence shows that the proportions of mental illnesses [8] and interpersonal distrust [9] across societies are correlated with income inequality. Moreover, large-scale processes 
of globalisation are affecting social relations in the workplaces and in society as a whole. In the last thirty years, as inequality in wealth and income continued to increase over time, societies have been characterised by growing feelings of social distrust [10], anxiety [11], depression [12] and external locus of control [13]. Can interventions aiming at improving social relations at work be effective if the corrosive social effects of an increasingly unequal and dysfunctional society remain unaddressed? This may not necessarily be the case. Nevertheless, more participative and democratic management structures as well as organizational fairness can positively influence social relationships and depression, for example, by reducing work stress and increase sense of control people have over how they do their work. Participative management and fairness at work may also reduce the experience of subordination and come closer to creating the trust, cooperation and participation that appear, like social networks and friendship [7] to be protective of good health. Perhaps, the most promising way to promote a friendlier and more cooperative work environment is to promote employee ownership schemes [14] where workers may participate not only in the shares and decision-making processes of their companies, but also feel a sense of "psychological ownership" that could reduce distrust, stress and depression. Last but not least, employee ownership schemes may also play a potential role in reducing income inequality that, in turn, could result in reducing psychosocial problems and depression in society as a whole. Whether this is true or not remain, however, an issue for future research investigations. 


\section{Disclosure:}

The Corresponding Author has the right to grant on behalf of all authors and does grant on behalf of all authors, an exclusive license (or non exclusive for government employees) on a worldwide basis to the BMJ Publishing Group Ltd and its Licensees to permit this article (if accepted) to be published in JECH and any other BMJPGL products to exploit all subsidiary rights, as set out in our licente (http://jech.bmjjournals.com/ifora/licence.pdf).

\section{Competing interests:}

None declared. 


\section{References}

1. House JS, Landis KR, Umberson D: Social relations and health. Science 1988, 241:540-545.

2. Kawachi et al. Social capital, income inequality and health. Am J Public Health 1997;87(9)1409-11.

3. Oksanen T, Kouvonen A, Kivimäki M, et al. Social capital at work as a predictor of employee health: Multilevel evidence from work units in Finland. Soc Sci Med 2008;66:637-49.

4. Kouvonen A, Oksanen T, Vahtera J, et al. Low workplace social capital as a predictor of depression. The Finnish Public Sector Study. Am J Epidemiol 2008;167:1143-51.

5. Oksanen T, Kouvonen A, Vahtera J, Virtanen M, Kivimäki M. Prospective study of workplace social capital and depression: Are vertical and horizontal components equally important? J Epidemiol Community Health.

6. De Vogli R, Ferrie J, Chandola T. Kivimaki M, and Marmot M. Unfairness and Health: Evidence form the Whitehall II study. J Epidemiol Community Health. 2007 Jun;61(6)513-8.

7. Stansfeld S. (1999) Social support and social cohesion. In: Marmot MG, Wilkinson RG. The Social Determinants of Health. Oxford University Press.

8. Pickett, K. E, James, O. W, Wilkinson, R. G. Income inequality and the prevalence of mental illness: a preliminary international analysis. $J$ Epidemiol. Community Health 2006 60: 646-647

9. Uslaner E and Brown M. Inequality, trust and civic engagement. American Politics Research 2005;33:868.

10. Layard R. Happiness: Lessons from a new science. London: Penguin Books, 2005.

11. Twenge J. The Age of Anxiety? Birth Cohort Change in Anxiety and Neuroticism, 1952-1993. J Personality and Social Psychology 2000;79:1007-1021.

12. Klerman G, Weissmann M. 1989. JAMA Increasing rates of depression;261:2229-2235.

13. Twenge J et al. It's Beyond My Control: A cross-temporal meta-analysis of increasing externality in locus of control, 1960-2002. Personality and Social Psychology Review, 8, 308-319.

14. NCEO (2004). Employee Ownership and Corporate Performance: a comprehensive review of the evidence. The National Center for Employee Ownership, Oakland. http://www.nceo.org/library/corpperf.html. 